\title{
Detection of Three Allelic Variants in the Rabbit Growth Hormone Gene*
}

\section{A. C. Cattáneoํㅗㄹ M. S. Trigo², L. O. Perez¹, C. A. Cordiviola², A. G. Antonini 1}

${ }^{1}$ IGEVET - Instituto de Genética Veterinaria (UNLP-CONICET LA PLATA), Facultad de Ciencias Veterinarias, UNLP, Calle 60 y 118 S/N, La Plata, Argentina

${ }^{2}$ Cátedra de Introducción a la Producción Animal, Facultad de Ciencias Agrarias y Forestales, UNLP, Calle 60 y 120 $\mathrm{S} / \mathrm{N}$, La Plata, Argentina

*This work was funded by Scientific Programs of National University of La Plata

\begin{abstract}
Background: The aim of this study was to identify molecular variants in a DNA fragment of the rabbit growth hormone gene and assess their relative contribution in trials with different dietary protein sources and protein levels. We studied 52 rabbits from 22 matings at the Experimental Unit of the School of Agricultural Sciences and Forestry, National University of La Plata. Diets contained two protein levels (14 and 17\%) and three protein sources (meat, fish and feather meal). We evaluated the different single nucleotide polymorphism (SNP) alleles and existing genotypes, and recorded the following productive variables: weaning weight (WW), weight at 45 days (W45), weight at slaughter (WS) and hot carcass weight (HCW).

Results; Three SNP variants (c.-49C $>$ A, c.-33A $>$ G and c.66G $>A$ ) were detected in the DNA fragment analyzed with two alleles. Whereas c. $-49 \mathrm{C}>\mathrm{A}(\mathrm{CC}, \mathrm{AC})$ and c.66G $>\mathrm{A}(\mathrm{GG}, \mathrm{AG})$ had only two genotypes, and C-33A $>\mathrm{G}$ had the three possible ones. Molecular variants were in equilibrium and two showed association $(p<0.001)$. The main contributor to overall phenotypic variation was $\mathrm{HCW}$, followed by level and type of protein, and presence of c.49C $>$ A alleles associated with the growth hormone gene.

Conclusions: The results reported in this study show the greater impact of changes in the levels and sources of protein in the diet on the percentage of variation in productivity than the presence or absence of a particular allele.
\end{abstract}

Keywords: Single nucleotide polymorphism; Animal Production; Genetics

\begin{abstract}
Background
Molecular biology research has become a useful tool to understand the genetics and expression of living beings through techniques that complement the traditional production intensification and improvement system. Knowledge of animal genomes has allowed the identification and location of genes related to growth and production in species of zootechnical interest (García, 2006). Evaluation of the so-called "candidate genes" is possible through the direct application of molecular techniques in order to identify their alternative forms or alleles and how these affect final production.
\end{abstract}

A mutation is a stable and heritable change in the genetic material that alters the DNA sequence and introduces new variants. Although many of these variants do not pass on to the next generation for different reasons, occasionally some of them succeed and are incorporated into the population. The most common type of genetic variation is the substitution of one base for another at a specific genome site. Such variation is called single nucleotide polymorphism (SNP) and occurs in more than one percent of the population. Each different base in that particular location is an allele.

The relative economic weight of the traits of interest in rabbit meat production at a particular establishment depends on population variation, environmental factors and the relationship among the traits directly or indirectly involved. Quantification of the relative contribution of each variable is important to properly rank their impact on total phenotypic variation. In this context, the identification of genetic markers associated with economic parameters could

This article is published under the terms of the Creative Commons Attribution License 4.0

Author(s) retain the copyright of this article. Publication rights with Alkhaer Publications.

Published at: http://www.ijsciences.com/pub/issue/2017-03/

DOI: 10.18483/ijSci.1208; Online ISSN: 2305-3925; Print ISSN: 2410-4477 
be the first step to incorporate this information into the indicators traditionally used to enhance productivity in intensive systems (Antonini, 2007).

The protein encoded by the growth hormone gene plays an important role in postnatal growth and in the regulation of many metabolic functions, including intramuscular fat deposition, lipid metabolism and bone growth. Some specific regions of the growth hormone gene have been analyzed as part of animal breeding programs in several especies (Regitano, 2005). The polymorphisms found showed association with production traits such as milk production, birth weight and carcass yield in bovines (García, 2006). Recently, Fontanesi et al. (2013) identified polymorphisms in the growth hormone gene and established association between their genotypes and rabbit weight at slaughter (Antonini, 2007).

The formulation of rations with better nutrient composition, the reduction of fecal contamination and the use of alternative protein sources to partially replace those that could be consumed by humans are particularly interesting. Such information could be applied to improve the efficiency of the production system and allow the use of products from other farms which would otherwise become waste, thus attenuating the detrimental environmental impact of intensive production. Feather meal, a protein-rich and highly available waste product obtained from poultry processing industries, is one of such alternative sources of protein.

The aim of this study was to identify the molecular variants in a DNA fragment of the rabbit growth hormone gene and assess their relative contribution in trials with different dietary protein sources and protein levels.

\section{Methods}

The study sample included 52 rabbits of both sexes obtained from 22 matings at the Experimental Unit of the Introduction to Animal Production Department, School of Agricultural Sciences and Forestry, National University of La Plata. All the animals belonged to an intensive breeding system and were housed in cages with food and water suited to their metabolic needs. This production was regulated and authorized by the Institutional Committee for the Care and Use of Laboratory Animals under protocol number 22.2.12T.

Blood samples $(3 \mathrm{ml})$ were collected in EDTA tubes. DNA extraction was performed at IGEVET (Instituto de Genética Veterinaria, UNLP-CONICET LA PLATA) using the Organic Extraction Protocol (Ali et al. 2016). Polymerase chain reactions (PCR) and sequencing of a fragment of the growth hormone gene were performed using a pair of primers designed by Fontanesi et al. (2012) and Wallis \& Wallis (1995) (Table 1, Figure 1). Then, the extracted DNA and sequence data were sent to Macrogen Inc. (Seoul, Korea) for sequencing. The sequenced data identified the alleles and genotypes of the fragment investigated for each animal and were displayed as electropherograms (Figure 2) and sequences in FASTA format.

We also recorded the following productive variables: weaning weight (WW), weight at 45 days (W45), weight at slaughter (WS) and hot carcass weight (HCW). Concerning diets, they had two protein levels $(14 \%$ and $17 \%)$ and three sources of protein (meat, fish and feather meal).

With the data obtained, we ran principal component analysis to generate the corresponding equations and weigh the contribution of the different genetic and environmental components to the observed variation.

\section{Results}

Three SNP (c. $-49 \mathrm{C}>\mathrm{A}$, c. $-33 \mathrm{~A}>\mathrm{G}$ and c.66G $>\mathrm{A}$ ) were detected in the study sample for the fragment analyzed. All SNP showed two alleles; c.-49C $>$ A presented only two genotypes $(\mathrm{CC}, \mathrm{AC})$, c.-33A $>\mathrm{G}$ the three possible genotypes, and c.66G $>A$ just two of them (GG, AG) (Table 2). Whereas two of the SNP (c. $-49 \mathrm{C}>\mathrm{A}$ and c.66G $>\mathrm{A}$ ) had two alleles that formed two different genotypes, c-33A $>\mathrm{G}$ had two alleles that formed three different genotypes (Figure 4). In all cases, the molecular variants were in equilibrium, with c. $-33 \mathrm{~A}>\mathrm{G}$ and $\mathrm{c} .66 \mathrm{G}>\mathrm{A}$ showing association $(\mathrm{p}$ $<0.001)$.

The main contributors to overall phenotypic variation were HCW (40.6\%), type of protein (17.5\%), protein concentration $(14.6 \%)$, the combination of the last two $(11.5 \%)$, and genotypic variation (presence or absence of certain c.-49C $>$ A alleles in the growth hormone gene) (10.4\%) (Table 3).

\section{Discussions}

Most research related to gene expression and its impact on the growth of individuals has been carried out in species of major economic importance, such as cattle and pigs (Regitano 2005; Van Laere et al. 2003). However, and despite the fact that genetic differences among species are relevant, similarities at molecular level can be used to establish different patterns and design trials in other species.

In our study, all the individuals analyzed were homozygous for $\mathrm{T}$, contrary to what was reported by Fontanesi et al. (2012) for c. $-78 \mathrm{C}>\mathrm{T}$, which presented two alleles ( $\mathrm{C}$ and $\mathrm{T}$ ) and the three possible genotypes, and to that described by Wallis \& Wallis 
(1995), who only described the presence of C. While we detected variations in c. $-49 \mathrm{C}>\mathrm{A}$ and c. $66 \mathrm{G}>\mathrm{A}$, the mentioned authors described a single allele for each SNP (C and G, respectively) (Fontanesi et al. 2012; Wallis \& Wallis 1995).

Regarding c.-33A $>$ G, Fontanesi et al. (2012) noted the presence of $A$ and $G$, but almost all individuals had the AA genotype, with the exception of a heterozygous individual. Since the frequency of $\mathrm{G}$ was less than $1 \%$, these authors were unable to establish relationships between this marker and any of the studied productive traits. Although the frequency of $\mathrm{G}(0.23)$ was lower compared with $\mathrm{A}$ (0.77), the variation in genotype expression was higher and genotypes were found in Hardy-Weinberg equilibrium (Table 2). The present results show the impact of a single allelic variant on productivity, opposite to that reported by Fontanesi et al. (2012) who identified the effect of a genotype on productivity.

We have previously reported the weight and impact of production variables (Antonini 2007). Here, we further analyzed the quantitative variables related to the phenotypic expression of economically interesting traits, as well as variants at molecular level in known DNA regions related with growth factors. Thus, the study of productive variables, of their relationship with genetic markers and of the impact of each of these traits on population variation could be useful to target new breeding strategies to improve the productive performance of rabbits.

\section{Conclusion}

The results reported in this study show the greater impact of changes in the levels and sources of protein in the diet on the percentage of variation in productivity than the presence or absence of a particular allele.

The determination of different allelic forms in growth-related genes allows the study of possible associations with production traits. SNP detection in itself is not enough to determine that some SNP variation is responsible for a higher or lower yield. However, the systematic study of productivity, of the different genotypes and of fragments of the same gene, as well as of other genes related with growth and meat production, together with the monitoring of these changes in successive generations could be used as predictive tools of reproductive selection systems at early stages of life to maximize system efficiency.

\section{Ethics approval}

This production was regulated and authorized by the Institutional Committee for the Care and Use of

Laboratory Animals under protocol number 22.2.12T.

\section{Consent for publication}

Not applicable.

\section{Availability of data and materials}

Data sharing not applicable to this article as no datasets were generated or analysed during the current study

\section{Competing interests}

The authors declare that they have no competing interests.

\section{Author contributions.}

Conceived and designed the experiments: ACC, AA, LOP; Performed the experiments: MST, ACC; Analyzed the data: AA, ACC; Contributed reagents/materials/analysis tools: ACC, MST, LOP, CAC, AA).

\section{Acknowledgements}

The authors thanks to Jose Meroni and Orlando Gvozdriecki for the manteinance of the rabbits experimental unit. Thanks are also due to A. Di Maggio for manuscript correction.

\section{References}

1. Ali H., Jafar S., Qurat-ul-Ain. (2016) Optimized genomic DNA extraction by a modified organic phenol-chloroform method without using PCR for best results. Int. J. Res. Med. Sci., 4, 100-104.

2. Antonini A.G. (2007) Estrategia genética de producción, aptitud biológica y objetivos de selección en conejos para carne. Tesis. Facultad de Ciencias Veterinarias. UNLP. Available from: http://sedici.unlp.edu.ar/handle/10915/1584.

3. Fontanesi, L., Dall'Olio, S., Spaccapaniccia, E., Scotti, E., Fornasini, D., Frabetti, A., Russo, V. A (2012) Single nucleotide polymorphism in the rabbit growth hormone (GH1) gene is associated with market weight in a commercial rabbit population. Livest Sci, Volume 147, Issue 1, $84-88$.

4. Garcia, J.F. (2006) Utilização de Marcadores Moleculares para a Seleção. 2 Simpósio Internacional de Reprodução Animal Aplicada, Londrina. 61, 115-123.

5. Regitano, L.C.A. (2005) Genética Molecular Aplicada ao Melhoramento Reunião Anual da Sociedade Brasileira de Zootecnia, Goiânia, 30, 167-175.

6. Van Laere, A.S., Nguyen, M., Braunschweig, M., Nezer, C., Collette, C., Moreau, L., Archibald, A. L., Haley, C. S., Buys, N., Tally, M., Andersson, G., Georges, M. y Andersson, L. (2003) A regulatory mutation in IGF2 causes a major QTL effect on muscle growth in the pig. Nature, 425, 832-836.

7. Wallis, O.C., Wallis, M., (1995). Cloning and characterization of the rabbit growth hormone-encoding gene. Gene 163, 253-256. 